\title{
Analisa Efisiensi Generator pada Generator Sinkron Tiga Fasa dengan Penggerak Turbin Angin
}

\author{
Rifdian I.S ${ }^{1}$, Hartono ${ }^{2}$ \\ ${ }^{1,2}$ Politeknik Penerbangan Surabaya \\ J1. Jemur Andayani I, No. 73 Surabaya 60236 \\ Email : rifdian.anto@gmail.com
}

\begin{abstract}
ABSTRAK
Penelitian ini bertujuan mengembangkan pembangkit listrik tenaga bayu sebagai sumber energi alternatif untuk menghasilkan energi yang efisien, efektif dan handal. Alat ini dapat dimanfaatkan untuk memenuhi kebutuhan energi di daerah belum dijangkau PLN dan tidak berpengaruh terhadap cuaca sehingga dapat menghasilkan energi yang optimal. Alat ini dibuat dalam beberapa tahapan yaitu (1) verifikasi potensi kecepatan dan arah angin, (2) rencana penggunaan beban, (3) generator yang digunakan, dan (4) tahap uji generator. Tahap uji generator terdiri dari: (1) uji tahann isolasi, (2) pengujian polarisasi index, (3) pengujian tegangan lebih (4) pengujian step voltage. Alat ini bekerja menggunakan generator AC 3 phase. Salah satu jenis generator generator adalah generaror arus bolak balik untuk mengubah tenaga makanis menjadi tenaga listrik. Sumber penggerak dari generator tersebut menggunakan sumber energi angin. Berdasarkan hasil pengujian yang telah dilaksanakan maka dapat disimpulkan bahwa alat kincir Angin ini dapat bekerja dengan baik. Hal tersebut ditunjukan oleh hasil uji alat dengan baik dan data dapat terpenuhi. Efisiensi generator maksimum dan minimum yang dihasilkan berturut-turut adalah 20,68\% dan 3,10\% .
\end{abstract}

Kata Kunci : angin, sumber energi,

\section{PENDAHULUAN}

Saat ini masih banyak daerah di wilayah Indonesia yang belum tersentuh layanan listrik dari pihak pemerintah (PLN) maupun swasta. Presiden Susilo Bambang Yudhoyono saat mendeklarasikan Gerakan Indonesia Bebas Pemadaman Bergilir di Mataram, Nusa Tenggara Barat (NTB), Selasa 27 Juli 2014, menyatakan, sekarang terdapat 19 juta rumah tangga di Indonesia yang belum menikmati listrik, sehingga perlu ditempuh upaya-upaya nyata. Pemerintah terus berupaya sehingga pada akhirnya rakyat miskin bisa memperoleh aliran listrik. Disebutkan, di kawasan Indonesia bagian timur dan barat masing-masing ada 500.000 pemohon pelanggan listrik baru yang masih masuk dalam daftar tunggu memperoleh akses atas pelayanan listrik. Presiden mengatakan, Pemerintah baik daerah maupun pusat terus bekerja untuk mengatasi listrik seraya meningkatkan ketersediaan listrik untuk kepentingan rakyat.

Lebih lanjut Kepala Negara mengatakan, sediaan listrik di Indonesia sejak zaman Presiden Soekarno hingga tahun 2005 hanya berjumlah 25.000 MegaWatt yang seiring meningkatnya permintaan dari waktu ke waktu makin menunjukkan kekurangan.

Oleh karena itu, kata Presiden, pemerintah menggagas program 10.000 Megawatt tahap pertama dan kedua (KESDM, 27 juli 2014). Berawal dari permasalahan tersebut, muncul suatu ide untuk mengatasi masalah tersebut adalah dengan inovasi merancang bangun sebuah sistem pembangkit listrik rumah tinggal bertenaga angin. Asumsinya, seluruh wilayah di- Indonesia merupakan wilayah yang berada di sekitar garis katulistiwa, artinya setiap hari sepanjang tahun dipastikan ada angin di atas wilayah Indonesia. Sehingga pembangkitan 
energi listrik bertenaga angin ini sangat mungkin untuk diimplementasikan di seluruh wilayah Indonesia, bahkan di daerah-daerah terpencil dan pelosok desa atau pegunungan.

Sistem pembangkit listrik tenaga angin ini direncanakan dengan sumbu horizontal pada kincir angin yang mengubah energi angin menjadi arus listrik yang kemudian digunakan untuk mencharge battery. Sebuah inverter DC ke AC diaplikasikan untuk mengubah energi listrik DC dari battery menjadi energy listrik AC yang siap digunakan untuk penerangan rumah tinggal. Adapun spesifikasi dari daya keluaran yang dihasilkan dari sistem pembangkit listrik ini diorientasikan untuk konsumsi rumah tinggal sederhana. Kincir angin bersumbu horizontal ini memiliki beberapa komponen utama yang dapat dilihat secara fisik seperti: generator, tower, baling-baling/sudu, ekor, dan nacelle.

Pada umumnya kincir angin sumbu horizontal yang dikembangkan Indonesia dengan generator AC 3 phase memiliki batas kecepatan angin minimum dan maksimum untuk menggerakkannya. Hal tersebut dikarenakan dalam perancangan awal sistem konversi energi angin berupa kincir angin ini harus berdasarkan dengan data potensi kecepatan angin yang tersedia pada suatu daerah tertentu. Dengan kondisi tersebut dimana potensi kecepatan angin disetiap daerah mempunyai kemungkinan berbeda dengan daerah lain menyebabkan kincir angin ini tidak dapat ditempatkan pada daerah yang tidak sesuai dengan perancangan kincir angin tersebut. Oleh karena itu, generator yang digunakan kincir angin pada umumnya memiliki karakteristik tidak sesuai dengan kondisi angin. Pada kecepatan yang sangat rendah (yang sering terjadi juga karena besarnya fluktuasi). Akibatnya daya tidak terbangkitkan pada kecepatan rendah. Maka sistem turbin angin di Indonesia sering tidak menghasilkan daya (karena kecepatan sangat rendah cukup sering terjadi).

Berdasarkan uraian diatas, melihat potensi energi angin yang melimpah di Indonesia dan dapat digunakan menjadi Sistem Konversi Energi Angin (SKEA) dengan menggunakan kincir angin bersumbu horizontal yang mulai dikembangkan. Dengan ini penulis memiliki gagasan untuk membuat sebuah inovasi dari sebuah kincir angin bersumbu horizontal. Kincir angin tersebut menggunakan generator AC 3 phase yang dapat menghasilkan daya ouput pada kecepatan angin yang minimum maupun maksimum dengan menghasilkan generator yang efisien. Efisiensi generator AC adalah rasio output daya berguna untuk masukan daya total. Karena setiap proses mekanis pengalaman beberapa kerugian, tidak ada generator AC bisa $100 \%$ efisien maka perlunya menganalisis efisiensi generator.

\section{METODE PENELITIAN}

Metode dalam penelitian ini adalah dengan menganalisisis kebutuhan sistem, perencanaan konsep alat dan pengidentifikasian kebutuhan sistem.

Identifikasi kebutuhan sistem dalam penelitian ini meliputi:

1. Verifikasi potensi kecepatan dan arah angin.

2. Rencana penggunaan beban.

3. Generator yang digunakan, dan tahap uji generator. Tahap uji generator terdiri dari: uji tahanan isolasi, pengujian polarisasi index, pengujian tegangan lebih pengujian step voltage.

\section{Potensi Kecepatan dan Arah Angin}

Potensi kecepatan dan arah angin digunakan sebagai acuan dasar dalam perancangan dan pengujian unjuk kerja kincir angin. Dalam pengukuran potensi kecepatan angin dan arah angin dapat menggunakan alat anemometer. Data hasil pengukuran kecepatan dan arah angin yang berlokasi di Pantai Baru, Bantul yang akan dijadikan tempat pengujian unjuk kerja kincir angin ini menggunakan data dari hasil observasi pengukuran sistem telemetri pada pukul 11.00 hingga pukul 17.00 pada lokasi tersebut. Data observasi kecepatan angin yang tercatat pada sistem telemetri di Pantai Baru ditampilkan dalam tabel 1. 
Tabel 1. Data Observasi Kecepatan Angin di Pantai Baru

\begin{tabular}{|c|c|c|}
\hline No & Waktu & $\begin{array}{c}\text { Kecepatan } \\
\text { Angin (m/s) }\end{array}$ \\
\hline 1 & 1 menit & 4.98 \\
\hline 2 & 2 menit & 4.5 \\
\hline 3 & 4 menit & 4.62 \\
\hline 4 & 6 menit & 5.36 \\
\hline 5 & 8 menit & 4.98 \\
\hline 6 & 10 menit & 3.83 \\
\hline 7 & 12 menit & 4.5 \\
\hline 8 & 14 menit & 4.52 \\
\hline 9 & 16 menit & 4.98 \\
\hline 10 & 18 menit & 4.5 \\
\hline 11 & 20 menit & 4.52 \\
\hline 12 & 22 menit & 4.5 \\
\hline 13 & 24 menit & 4.5 \\
\hline 14 & 26 menit & 4.5 \\
\hline 15 & 28 menit & 4.32 \\
\hline 16 & 30 menit & 4.2 \\
\hline 17 & 32 menit & 4.26 \\
\hline 18 & 34 menit & 4.2 \\
\hline 19 & 36 menit & 4.62 \\
\hline 20 & 38 menit & 4.36 \\
\hline 21 & 40 menit & 4.98 \\
\hline 22 & 42 menit & 5.75 \\
\hline 23 & 44 menit & 5.75 \\
\hline 24 & 46 menit & 5.5 \\
\hline 25 & 48 menit & 5.36 \\
\hline 26 & 50 menit & 4.62 \\
\hline 27 & 52 menit & 4.2 \\
\hline 28 & 54 menit & 5.36 \\
\hline 29 & 56 menit & 4.98 \\
\hline 30 & 58 menit & 4.5 \\
\hline 31 & 60 menit & 5.36 \\
\hline
\end{tabular}

\section{Rencana Penggunaan Beban}

Rencana penggunaan beban pada kincir angin ini tidak dapat digunakan secara langsung (direct), melainkan digunakan secara tidak langsung (indirect) dengan media penyimpanan energi listrik terlebih dahulu. Hal tersebut dikarenakan potensi kecepatan angin yang menggerakan kincir angin selalu berubah-ubah sehingga berpengaruh terhadap tegangan yang dihasilkan kincir angin yang tentu akan ikut berubah.

Penyimpanan energi listrik dapat menggunakan baterai yang dapat menyimpan dengan kapasitas tertentu. Rencana penggunaan beban pada sistem ini menggunakan baterai yang diharapkan dapat menyimpan tegangan secara optimal sebelum digunakan. Spesifikasi dan bentuk fisik baterai sebagai berikut:

Tabel 2. Spesifikasi Baterai

\begin{tabular}{ccc}
\hline Merk & Tegangan & Arus \\
\hline Yuasa (YB5L-B) & $12 \mathrm{~V}$ & $5 \mathrm{Ah}$ \\
\hline
\end{tabular}




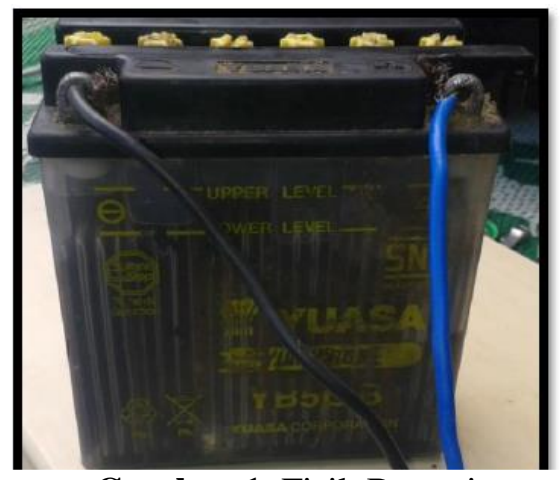

\section{Generator yang Digunakan}

Gambar 1. Fisik Baterai

Generator yang digunakan sebagai konversi tenaga kinetik yang dihasilkan oleh tenaga angin pada sistem kincir angin ini merupakan generator AC 3 phase.

Pemilihan menggunakan generator AC 3 phase ini karena generator 3 phase memiliki daya output yang lebih besar dengan dimensi ukuran fisik yang lebih kecil dibandingkan dengan generator 1 phase yang memiliki daya yang sama.

Menurut Sunyoto (1993: 20-21), Di dalam generator arus searah dikenal tiga macam daya yaitu daya masukan (Pin), daya pada jangkar (daya dalam Pa), dan daya keluaran (Pout). Daya masukan adalah daya yang digunakan untuk memutar rotor generator. Daya pada jangkar (daya dalam) adalah daya yang dihasilkan oleh lilitan jangkar sedangkan daya keluaran adalah daya yang dipakai oleh beban.

Perbandingan antara daya keluaran P1 dengan daya masukan Pm disebut efisiensi generator dan dinyatakan dengan persamaan:

$$
\eta G=\frac{\text { Pout }}{\text { Pin }} \times 100 \%
$$

Keterangan:

Pout $=$ daya keluaran

Pin = daya masukan

Spesifikasi dan bentuk fisik generator sebagai berikut:

Tabel 3. Spesifikasi Generator

\begin{tabular}{ccccc}
\hline Merk & F & Rpm & Tegangan & Daya \\
\hline PPAFF & $50 \mathrm{~Hz}$ & 3000 & $380 \mathrm{~V}$ & $250 \mathrm{~W}$ \\
\hline
\end{tabular}

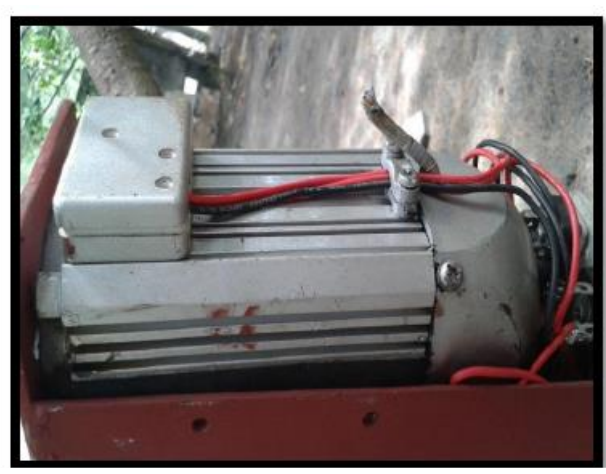

Gambar 2. Fisik Generator 


\section{Tahap Uji Generator}

Tahap uji generator sebagai pembangkit listrik tenaga angin sangat dipengaruhi beberapa faktor seperti: potensi tenaga angin yang terdapat pada daerah tersebut dan rencana penggunaan beban. Potensi tenaga angin berpengaruh terhadap kecepatan angin untuk menggerakan kincir angin dalam keadaan kecepatan angin minimum ataupun maksimum dan mempengaruhi besaran dari hasil keluaran generator kincir angin seperti: tegangan (V). Sedangkan, penggunaan beban berpengaruh terhadap arus (I) dan daya listrik (P) yang akan dihasilkan kincir angin tersebut.

\section{Pengujian Tahanan Isolasi}

Pengujian ini dilakukan untuk mendeteksi adanya kelemahan isolasi tahanan. Pengujian isolasi secara rutin dapat dilakukan dengan menggunakan Megaohmmeter, atau megger yang pembacaannya langsung dalam meghoms. Tahanan isolasi adalah ukuran kebocoran arus yang melalui isolasi. Tahanan berubah-ubah karena pengaruh temperatur dan lamanya tegangan yang diterapkan pada lilitan tersebut, oleh karena itu faktor-faktor tersebut harus dicatat pada waktu pengujian. Tegangan yang diterapkan kalau bisa hanya pada satu fasa saja. Nilai tegangan minimum pengujian yang banyak digunakan dan diterima dikalangan praktisi adalah satu kilovolt sebanding dengan satu (1) megaohm terhadap peralatan listrik yang banyak digunakan pada industri-industri (untuk lilitan stator), dan satu (1) megaohm untuk lilitan rotor setelah dikenai tegangan 500 volt dc selama satu menit. Generatorgenerator turbin hampir selalu mempunyai nilai lebih tinggi. Tegangan 500 volt dc untuk pengujian ini harus dilakukan terlebih dahulu sebelum pengujian tegangan yang lebih tinggi dilakukan. Nilai tahanan diatas merupakan nilai minimum yang menunjukkan bahwa keadaan lilitan masih baik, nilai tahanan yang rendah dapat menunjukkan lilitan dalam keadaan kotor atau basah. Moisture dapat juga terdapat pada permukaan isolasi, atau pada lilitan atau pada keduanya. Oleh sebab itu, pengujian dengan megger sebelum dan sesudah mesin dibersihkan harus dilakukan. Jika nilai tahanan tetap rendah dan lilitan relatif bersih, ada kemungkinan adanya moisture pada lilitan, dan lilitan harus dikeringkan sekurang-kurangnya sampai diperoleh tahanan minimum yang dianjurkan.

Pengujian Polarisasi Index Pengujian untuk menentukan keadaan isolasi yang baik adalah membandingkan hasil tahanan setelah pengujian tegangan selama 10 menit dengan tahanan pada saat satu menit pertama. Jika pengujian dilakukan sebelum dan sesudah mesin dibersihkan, dan atau sesudah mesin dikeringkan, akan menunjukkan hasil pengukuran yang lebih baik. Polarisasi index test merupakan petunjuk kekeringan dan kebersihan dari lilitan, dan hasilnya akan menentukan apakah peralatan aman untuk dioperasikan dan atau peralatan untuk dilakukan pengujian tegangan lebih. Untuk stator, pengujian PI menggunakan tegangan $2,5 \mathrm{kV}$ dc (tegangan rating generator $13.8 \mathrm{kV}, 50 \mathrm{hz}, 3$ fasa). Jika PI adalah sama atau lebih besar dua (2), maka pengujian dengan tegangan $6 \mathrm{KV}$ dc dapat dilakukan. PI untuk pengujian dengan $6 \mathrm{KV}$ dc harus lebih besar atau sama dengan 2. Untuk rotor, tegangan $500 \mathrm{Vdc}$ dapat digunakan tanpa melepaskan atau menghubung singkatkan diode. Jangan menggunakan tegangan lebih dari $500 \mathrm{~V}$ dc tanpa mengetahui hasil pengujian dengan tegangan $500 \mathrm{~V}$ dc. Jika digunakan tegangan yang lebih tinggi, diode harus dilepas. Tahanan rotor pada pengujian tahanan dengan menggunakan tegangan $500 \mathrm{~V}$ dc harus lebih dari 50 megohm dan PI untuk tegangan $500 \mathrm{~V}$ dc harus lebih besar dari dua (2). Tegangan maksimum yang diizinkan adalah $1500 \mathrm{~V}$ ac atau $2500 \mathrm{~V}$ dc.

\section{Pengujian Tegangan Lebih}

Pengujian tegangan lebih dimaksudkan untuk menemukan kelemahan pada lilitan stator yang harus diperbaiki. Pengujian ini juga digunakan untuk meyakinkan bahwa lilitan mempunyai 
ketahanan dielektrik yang cocok untuk dioperasikan. Pengujian ini dapat dilakukan dengan menggunakan tegangan ac $(50 \mathrm{hz})$ atau arus searah. Tingkat tegangan yang diterapkan sangat tergantung pada tipe mesin, pelayanannya, isolasinya, dan pengalaman pemakai didalam pengujian tegangan tinggi. pengujian arus bolak-balik biasanya dilakukan dengan menggunakan tegangan sebesar 1,5 kali tegangan jala-jala. Sedangkan pengujian dengan tegangan arus searah kira-kira 1,7 kali pengujian AC atau sekitar 2,7 kali tegangan nominal jala-jala.

\section{Pengujian Step Voltage}

Pada pengujian ini, generator dilepaskan dari sistem pengendali dan semua peralatan bantunya, dan hubungkan alat penguji tegangan tinggi dc antara satu fasa lilitan generator dengan metal generator. Tegangan dinaikkan selangkah demi selangkah dan arus bocordapat kita baca dan data tersebut dicatat. Arus yang terbaca pertama kali sebelum arus menjadi stabil yang merupakan arus bocor yang dapat dinyatakan arus sebagai fungsi waktu terdiri dari tiga komponen yaitu:

1. Arus pengisian pada lilitan terhadap kapasitas tanah. Arus ini dengan cepat turun dari maksimum menjadi nol.

2. Arus absorsi pada pergeseran molekul pengisian pada dielektrik. Arus peralihan ini akan berkurang dengan waktu yang sangatlambat untuk menjadi nol.

3. Arus bocor yang merupakan arus penghantar sebenarnya dari dielektrik, arus bocor akan berubah-ubah tergantung tegangan yang diterapkan. Arus ini dapat juga terdiri dari arus bocor permukaan..

Pada pengujian ini, temperatur, kelembaban, dan keadaan sekelilingnya harus dicatat. Penghantar penguji harus berukuran 12 AWG atau lebih, dan diatur agar bebas dari pengaruh kehilangan (kerugian) korona. Semua peralatan bantu seperti penditeksi temperatur, lilitan fasa yang tidak diuji, dan lilitan rotor harus ditanahkan sebelum dilakukan pengujian. Hal ini perlu, karena setelah pengujian pengisian dapat dilepaskan dengan aman. Terapkan tegangan $10 \mathrm{kV}$ pada saat mulai melakukan pengujian dan naikkan setiap tingkat sampai tercapai nilai tegangan 2.7 kali tegangan jala-jala. Tahanan isolasi dapat dihitung pada setiap tingkat dengan menggunakan hukum ohm. Tahanan isolasi $(\mathrm{megOhm})=$ tegangan pengujian/ arus bocor. Arus bocor yang terbaca biasanya dalam mikro amper.

\section{HASIL PENGUJIAN dan ANALISA}

Pengujian unjuk kerja kincir angin ini untuk mengetahui analisis efisiensi generator pada Wind Turbine dan sistem operasi Wind Turbine. Pengujian unjuk kerja ini dilakukan untuk mendapatkan hasil yang sesuai agar dapat menanalisis efisiensi generator.

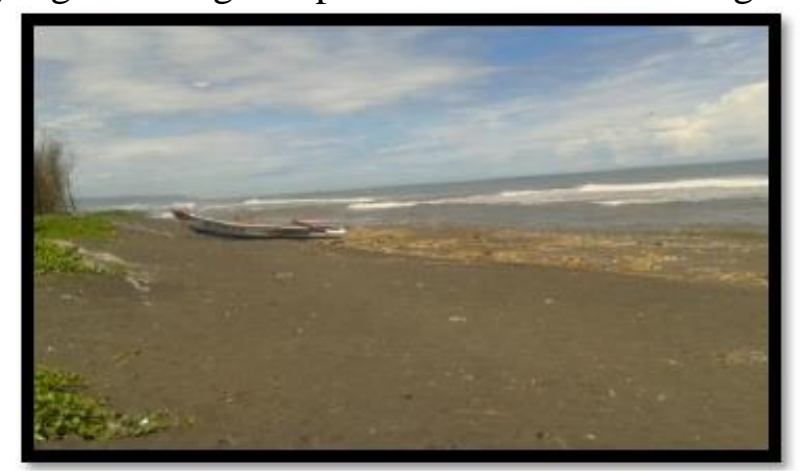

Gambar 3. Lokasi Tempat Pengujian dan Pengambilan Data Kincir Angin 
Tabel 4. Hasil Pengujian Kincir Angin.

\begin{tabular}{|c|c|c|c|c|c|c|c|}
\hline No. & $\begin{array}{c}\text { Waktu } \\
\text { (menit) }\end{array}$ & $\begin{array}{l}\text { Kec. } \\
\text { Angin } \\
(\mathbf{m} / \mathrm{s})\end{array}$ & $\begin{array}{c}\text { Open } \\
\text { Circuit } \\
\text { (Rpm) }\end{array}$ & $\begin{array}{c}\text { Open } \\
\text { Circuit } \\
\text { (Vdc) }\end{array}$ & $\begin{array}{l}\text { Close } \\
\text { Circuit } \\
\text { (Rpm) }\end{array}$ & $\begin{array}{l}\text { Close } \\
\text { Circuit } \\
\text { (Vdc) }\end{array}$ & $\begin{array}{c}\text { Arus } \\
\text { (I) }\end{array}$ \\
\hline 1 & 1 & 4,98 & 858,20 & 20,40 & 836,60 & 13,40 & 0,40 \\
\hline 2 & 2 & 4,50 & 820,20 & 18,10 & 800,00 & 14,40 & 0,50 \\
\hline 3 & 4 & 4,62 & 865,10 & 19.40 & 836,00 & 13,80 & 0,50 \\
\hline 4 & 6 & 5,36 & 964,20 & 23,20 & 936,50 & 15,10 & 1,10 \\
\hline 5 & 8 & 4,98 & 868,20 & 21,60 & 850,20 & 13,50 & 0,50 \\
\hline 6 & 10 & 3,83 & 658,20 & 16,20 & 630,10 & 12,10 & 0,20 \\
\hline 7 & 12 & 4,50 & 820,20 & 18,10 & 800,00 & 14,40 & 0,50 \\
\hline 8 & 14 & 4,52 & 819,10 & 18,10 & 801,70 & 14,50 & 0,50 \\
\hline 9 & 16 & 4,98 & 868,20 & 21,50 & 845,10 & 15,00 & 1,00 \\
\hline 10 & 18 & 4,50 & 820,20 & 18,00 & 798,30 & 14,40 & 0,50 \\
\hline 11 & 20 & 4,52 & 820,10 & 18,10 & 800,80 & 14,10 & 0,50 \\
\hline 12 & 22 & 4,50 & 819,70 & 17,90 & 799,10 & 14,90 & 0,50 \\
\hline 13 & 24 & 4,50 & 825,00 & 18,90 & 800,10 & 14,80 & 0,50 \\
\hline 14 & 26 & 4,50 & 823,10 & 18,50 & 802,10 & 14,10 & 0,50 \\
\hline 15 & 28 & 4,32 & 815,10 & 18,50 & 781,10 & 14,10 & 0,50 \\
\hline 16 & 30 & 4,20 & 789,10 & 17,20 & 752,10 & 12,20 & 0,20 \\
\hline 17 & 32 & 4,26 & 780,20 & 17,00 & 760,10 & 12,10 & 0,20 \\
\hline 18 & 34 & 4,20 & 785,10 & 17,20 & 752,10 & 12,20 & 0,20 \\
\hline 19 & 36 & 4,62 & 865,20 & 19,50 & 840,10 & 14,10 & 0,60 \\
\hline 20 & 38 & 4,36 & 960,10 & 22,70 & 890,20 & 18,20 & 1,00 \\
\hline 21 & 40 & 4,98 & 868,20 & 21,00 & 842,10 & 17,10 & 0,80 \\
\hline 22 & 42 & 5,75 & 991,00 & 25,60 & 980,20 & 20,20 & 1,10 \\
\hline 23 & 44 & 5,75 & 990,60 & 25,10 & 980,10 & 20,10 & 1,10 \\
\hline 24 & 46 & 5,50 & 975,40 & 24,30 & 896,00 & 19,60 & 1,00 \\
\hline 25 & 48 & 5,36 & 964,20 & 23,20 & 936,50 & 15,40 & 1,00 \\
\hline 26 & 50 & 4,62 & 865,20 & 18,10 & 797,30 & 14,30 & 0,50 \\
\hline 27 & 52 & 4,20 & 785,00 & 17,10 & 760,40 & 12,40 & 0,20 \\
\hline 28 & 54 & 5,36 & 964,30 & 23,10 & 936,60 & 15,40 & 1,00 \\
\hline 29 & 56 & 4,98 & 986,50 & 21,40 & 968,70 & 13,50 & 0,50 \\
\hline 30 & 58 & 4,50 & 820,10 & 18,40 & 799,00 & 13,10 & 0,50 \\
\hline 31 & 60 & 5,36 & 960,40 & 22,90 & 945,10 & 15.40 & 1,00 \\
\hline
\end{tabular}

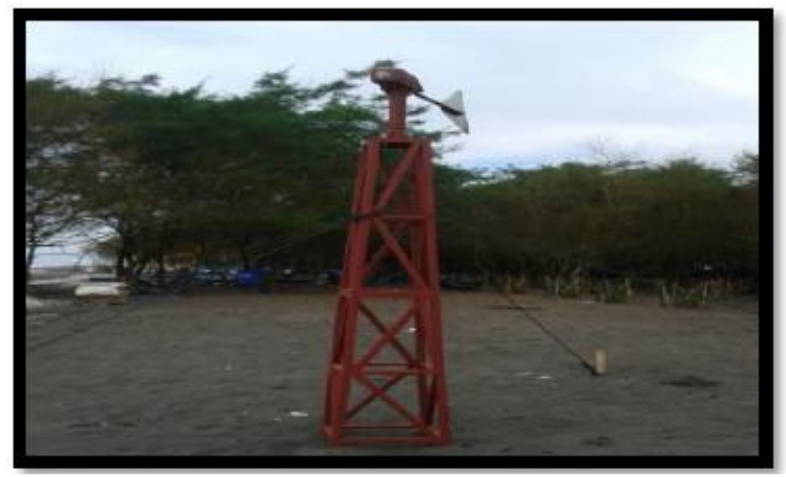

Gambar 4. Pemasangan Kincir Angin di Lokasi Pengujian dan Pengambilan Data

Gambar 3 dan 4 merupakan dokumentasi observasi tempat yang akan dijadikan tempat pengujian dan pengambilan data kincir angina.

Berikut ini merupakan data yang diperoleh setelah melakukan pengujian unjuk kerja kincir angin dengan berberban dan tidak berbeban. Hasil Pengukuran Tegangan (V), Arus (I), Kecepatan Rotasi Kincir Angin (Rpm) dan Kecepatan Angin (m/s) dengan variable perubahan Waktu (s) pada kincir angin. 


\section{Fungsi Kerja Komponen Kincir Angin}

Dari hasil pengujian fungsi kerja komponen kincir angin yang menggunakan generator AC 3 phase dengan arus bilak balik diperoleh fungsi kerja dari setiap komponen kincir angin dapat berkerja dengan baik. Pengujian ini dilakukan untuk mengetahui kesesuaian konsep perancangan kincir angin ini dengan proses pembuatan kincir angin tersebut. Hasil pengujian fungsi kerja komponen kincir angin yang dilakukan meliputi beberapa komponen kincir angin, sebagai berikut: pengujian generator terhadap perencanaan beban untuk mengetahui kinerja generator dalam menghasilkan listrik dapat berkerja dengan baik, pengujian generator saat tidak berbeban dapat menghasilkan data yang diinginkan dan bekerja dengan baik, dan pengujian tahanan isolasi.

\section{Analisis Data Hasil Pengujian Unjuk Kerja Generator dilihat dari Efisiensi}

Analisis data hasil pengujian unjuk kerja generator dilihat dari efisiensi ini dilakukan untuk mengetahui pengaruh perubahan efisiensi generator yang dihasilkan kincir angin ini. Analisis data hasil pengujian unjuk kerja kincir angin sebagai berikut:

a. Analisis Hasil Pengujian Kecepatan Angin dengan Waktu

Pengujian ini dilakukan untuk mengetahui kecepatan angin yang digunakan. Dari pengujian ini, diperoleh data berupa kecepatan angin. Pengujian dilakukan dengan menentukan waktu yang bervariasi dari mulai 1 menit - 60 menit. Pengujian dilakukan dengan menggunakan anemometer dari workshop di pantai baru agar mampu mengetahui hasil kecepatan angin $(\mathrm{m} / \mathrm{s})$ yang baik. Berdasarkan hasil pengujian kecepatan angin didapat hasil yang- maksimal $5,75 \mathrm{~m} / \mathrm{s}$. Hasil pengujian yang didapat dari pengujian ini ditunjukkan oleh Tabel 4.

Dari Tabel 4, dibuat grafik hubungan antara kecepatan angin $(\mathrm{m} / \mathrm{s})$ dengan waktu $(\mathrm{t})$.

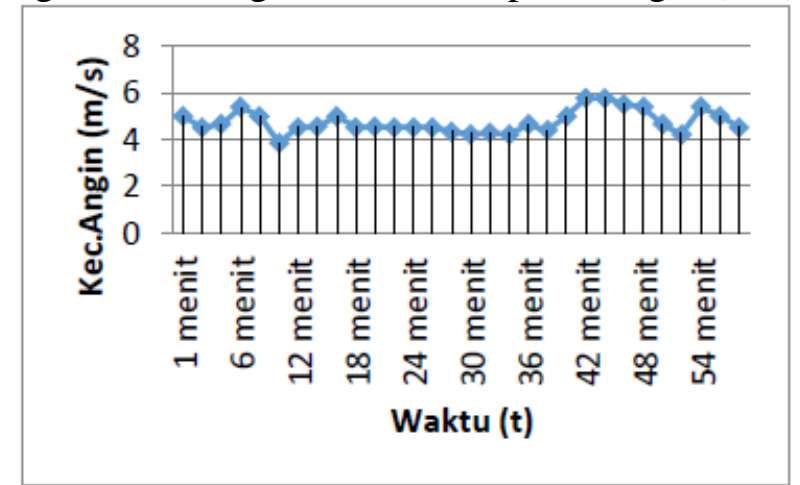

Gambar 5. Grafik Hubungan Antara Kecepatan Angin (m/s) dengan Waktu (t)

c. Analisis Pengujian Open Circuit (Vdc) \& Close Circuit (Vdc) dengan Waktu (t)

Pengujian ini dilakukan untuk mengetahui open circuit (Vdc) dan close circuit (Vdc) yang digunakan. Dari pengujian ini, diperoleh data berupa open circuit (Vdc) dan close circuit (Vdc). Pengujian dilakukan dengan menentukan waktu yang bervariasi dari mulai 1 menit - 60 menit. Pengujian dilakukan dengan menggunakan multimeter. Berdasarkan hasil pengujian open circuit $(\mathrm{Vdc})$ dan close circuit $(\mathrm{Vdc})$ didapat hasil yang maksimal 25,6 volt untuk open circuit dan close circuit 20,2 volt. Hasil pengujian yang didapat dari pengujian ini ditunjukkan oleh Tabel 4. Dari Tabel 4, dibuat grafik hubungan antara open circuit (Vdc) dan close circuit $(\mathrm{Vdc})$ dengan waktu $(\mathrm{t})$. 


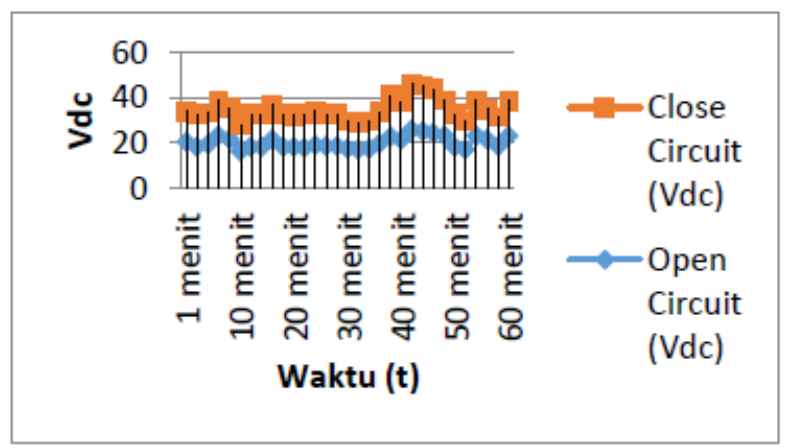

Gambar 6. Grafik Open Circuit (Vdc) dan Close Circuit (Vdc) dengan Waktu (t)

d. Analisis Pengujian Arus (I) dengan Waktu (t)

Pengujian ini dilakukan untuk mengetahui arus (I) yang digunakan. Dari pengujian ini, diperoleh data berupa arus (I). Pengujian dilakukan dengan menentukan waktu yang bervariasi dari mulai 1 menit - 60 menit. Pengujian dilakukan dengan menggunakan tang ampere. Berdasarkan hasil pengujian arus didapat hasil yang maksimal 1,1 ampere. Hasil pengujian yang didapat dari pengujian ini ditunjukkan oleh Tabel 4.

Dari Tabel 4, dibuat grafik hubungan antara arus (I) dengan waktu (t).

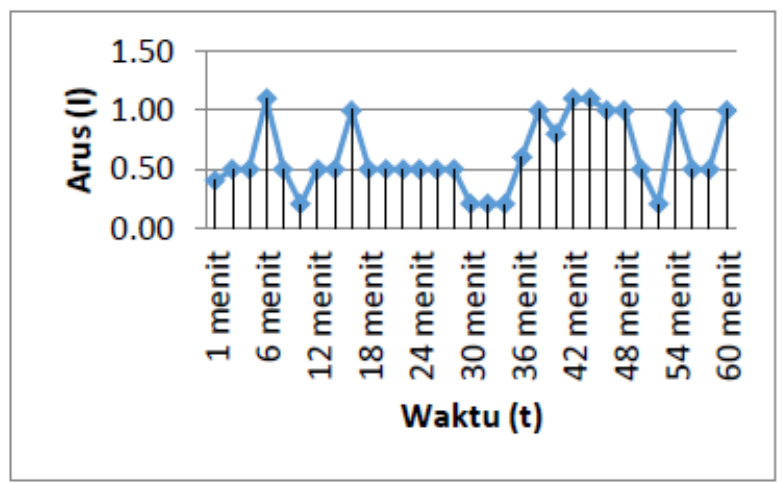

Gambar 7. Grafik Arus (I) dengan Waktu (t)

\section{e. Analisis Hasil Pengujian Karakteristik Output Generator}

Pengujian ini dilakukan untuk mengetahui karakteristik output generator yang digunakan. Dari pengujian ini, diperoleh data berupa tegangan listrik yang dihasilkan oleh generator. Pengujian dilakukan dengan menentukan besaran arus yang bervariasi dari mulai 0,2 Ampere sampai 1,1 Ampere. Putaran generator yang bergerak dengan sumber angin dapat mengetahui tegangan listrik keluaran generator. Pengujian dilakukan dengan mengatur rheostat agar mampu mengetahui kemampuan generator bekerja. Grafik hubungan antara arus listrik dengan tegangan listrik yang dihasilkan oleh generator adalah sesuai gambar 8 .

Gambar 8 menunjukkan bahwa arus keluaran generator sangat berpengaruh terhadap tegangan listrik yang dihasilkan oleh generator. Jika arus keluaran generator semakin tinggi, maka tegangan listrik yang dihasilkan oleh generator semakin menurun. Hal ini membuktikan bahwa arus listrik generatorberbanding terbalik dengan tegangan listrik yang dihasilkan oleh generator. Gambar 13, menunjukkan bahwa arus listrik generator sangat berpengaruh terhadap tegangan yang dihasilkan. 


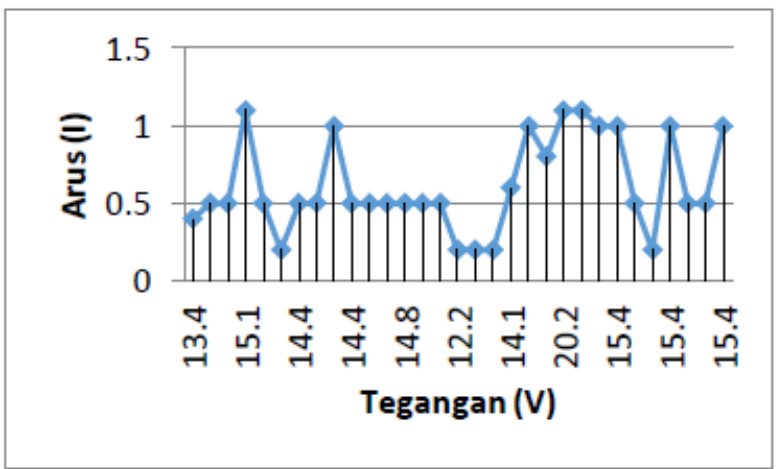

Gambar 8. Grafik hubungan Antara Arus Listrik dengan Tegangan Listrik yang dihasilkan oleh generator

Arus listrik yang dihasilkan oleh generator dapat dihitung dengan persamaan berikut:

Dimana: $\quad I=$ Arus listrik (Ampere)

$$
I=\frac{V}{R}
$$

$\mathrm{R}=$ Hambatan (ohm)

$\mathrm{V}=$ Tegangan listrik (Volt)

Besar arus listrik yang dihasilkan oleh generator akan menentukan daya output. Semakin besar arus listrik yang dihasilkan, semakin besar yang di hasilkan efisiensi generator. Sebaliknya, semakin kecil arus listrik yang dihasilkan oleh generator, semakin efisien yang di hasilkan efisiensi generator. Berdasarkan data pada Tabel 4, dapat dihitung daya listrik yang dapat dihasilkan oleh generator dengan persamaan berikut :

$$
\text { Pout }=V \times I
$$

keterangan:

$$
\begin{aligned}
& \text { Pout = daya output (Watt) } \\
& \text { I = arus listrik (Ampere) } \\
& \text { V = tegangan listrik (Volt) }
\end{aligned}
$$

Menurut perhitungan, daya listrik yang mampu dihasilkan oleh generator adalah sebagai berikut:

Pout $=$ V x I = 13,40 x 0,40 Pout $=5,36$ Watt

Tabel 5. Hasil Perhitungan Daya Listrik yang dihasilkan oleh-Generator

\begin{tabular}{cccc}
\hline No. & $\begin{array}{c}\text { Tegangan } \\
\text { (Volt) }\end{array}$ & $\begin{array}{c}\text { Arus } \\
\text { (Ampere) }\end{array}$ & Pout (Watt) \\
\hline 1 & 13,40 & 0,40 & 5,36 \\
2 & 14,40 & 0,50 & 7,2 \\
3 & 13,80 & 0,50 & 6,9 \\
4 & 15,10 & 1,10 & 16,61 \\
5 & 13,50 & 0,50 & 6,75 \\
6 & 12,10 & 0,20 & 2,42 \\
7 & 14,40 & 0,50 & 7,2
\end{tabular}




\begin{tabular}{cccc}
\hline No. & $\begin{array}{c}\text { Tegangan } \\
\text { (Volt) }\end{array}$ & $\begin{array}{c}\text { Arus } \\
\text { (Ampere) }\end{array}$ & Pout (Watt) \\
\hline 8 & 14,50 & 0,50 & 7,25 \\
9 & 15,00 & 1,00 & 15 \\
10 & 14,40 & 0,50 & 7,2 \\
11 & 14,10 & 0,50 & 7,05 \\
12 & 14,90 & 0,50 & 7,45 \\
13 & 14,80 & 0,50 & 7,4 \\
14 & 14,10 & 0,50 & 7,05 \\
15 & 14,10 & 0,50 & 7,05 \\
16 & 12,20 & 0,20 & 2,44 \\
17 & 12,10 & 0,20 & 2,42 \\
18 & 12,20 & 0,20 & 2,44 \\
19 & 14,10 & 0,60 & 8,46 \\
20 & 18,20 & 1,00 & 18,2 \\
21 & 17,10 & 0,80 & 13,68 \\
22 & 20,20 & 1,10 & 22,22 \\
\hline 23 & 20,10 & 1,10 & 22,11 \\
24 & 19,60 & 1,00 & 19,6 \\
25 & 15,40 & 1,00 & 15,4 \\
26 & 14,30 & 0,50 & 7,15 \\
27 & 12,40 & 0,20 & 2,48 \\
28 & 15,40 & 1,00 & 15,4 \\
29 & 13,50 & 0,50 & 6,75 \\
30 & 13,10 & 0,50 & 6,55 \\
31 & 15,40 & 1,00 & 15,4 \\
\hline
\end{tabular}

Dari Tabel 5, dibuat grafik hubungan antara arus listrik generator terhadap daya listrik yang dapat dihasilkan oleh generator. Gambar grafik dapat dilihat pada Gambar 10.

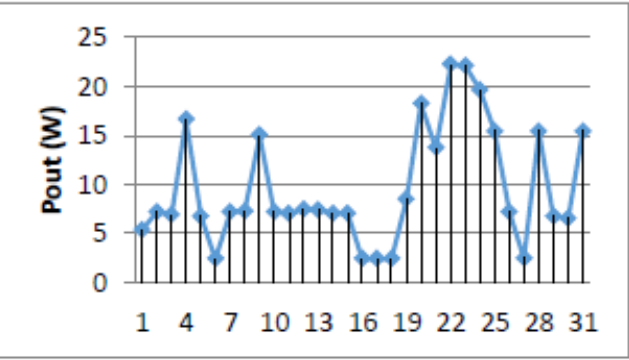

Gambar 9. Grafik Hubungan Antara Daya Listrik Yang Dihasilkan Generator Terhadap Arus Serta Tegangan Dari Generator

f. Analisis Hasil Pengujian Karakteristik Daya Input Kincir Angin

Pengujian ini dilakukan untuk mengetahui karakteristik inputan kincir angin yang digunakan. Dari pengujian ini, diperoleh data kepadatan udara, luas daerah sapuan sudu dan kecepatan angin. Pengujian dilakukan dengan menentukan kepadatan udara, luas daerah sapuan sudu dan kecepatan angin. Hasil pengujian yang didapat dari pengujian ini ditunjukkan oleh Tabel 6. Ukuran dimensi sudu/baling-baling/propeller sebagai berikut:

Panjang Sudu $=75 \mathrm{~cm}$ 
Lebar Bawah Sudu $=15 \mathrm{~cm}$

Lebar Atas Sudu $=10 \mathrm{~cm}$

Panjang Lengan Sudu $=30 \mathrm{~cm}$

Diameter Sudu Kincir Angin $=150 \mathrm{~cm}$

Jari-jari Sudu Kincir Angin $=75 \mathrm{~cm}$

Perhitungan Luasan Tiap Sudu :

Luas tiap sudu $=$ Panjang sudu $\mathrm{x}$ Jumlah lebar sudu $/ 2$

Luas Tiap sudu $=75 \times(15+10 / 2)$

Luas tiap sudu $=937,5$

Besar kecepatan angin yang dihasilkan oleh sumber angin di pantai akan menentukan daya input. Semakin besar pout yang dihasilkan, semakin besar yang di hasilkan efisiensi generator. Sebaliknya, semakin kecil pout sumber angin yang dihasilkan oleh angin, semakin efisien yang di hasilkan efisiensi generator. Data diatas, dapat dihitung daya listrik yang dapat dihasilkan oleh kincir dengan persamaan :

keterangan:

Daya Anagin $=1 / 2 \times$ q $x$ A $x$ (satuan dalam $\mathrm{m}$ )

$\mathrm{q}=$ Kepadatan Udara $(\mathrm{kg} / \mathrm{m} 3)$;

A = Luas Daerah Sapuan Sudu (m2);

$\mathrm{v}=$ Kecepatan Angin $(\mathrm{m} / \mathrm{s})$;

Menurut Abdul Kadir (1995:218), perhitungan daya angin pada sudu merupakan energi angin yang dihasilkan per satuan- waktu. Berdasarkan data-data ukuran sudu/baling-baling diatas, jika asumsi kecepatan angin $(\mathrm{v})=4,98 \mathrm{~m} / \mathrm{s}$ dan kepadatan udara $(\mathrm{q})=1,2 \mathrm{~kg} / \mathrm{m} 3$, maka daya angin yang dihasilkan angin adalah:

Pin $($ Daya Angin $)=1 / 2 \times$ q x A x v^3 (satuan dalam $\mathrm{m})$

Pin $($ Daya Angin $)=1 / 2 \times 1,2 \times 1,77 \times(4,98)^{\wedge} 3$

$\operatorname{Pin}($ Daya Angin $)=131,16 \mathrm{Watt}$

\section{g. Analisis Hasil Karakteristik Efisiensi Generator}

Pengujian ini dilakukan untuk mengetahui karakteristik efisiensi generator pada kincir angin yang digunakan. Dari pengujian ini, diperoleh data berupa daya input dan daya output. Pengujian dilakukan dengan menentukan luas sudu kincir angin. Putaran generator yang bergerak dengan sumber angin dapat mengetahui kecepatan angin.

Besar kecepatan angin yang dihasilkan oleh sumber angin di pantai akan menentukan analisis efisiensi generator. Semakin besar daya input yang dihasilkan, semakin kecil yang di hasilkan efisiensi generator. Sebaliknya, semakin kecil input sumber angin yang dihasilkan oleh angin, semakin besar yang di hasilkan efisiensi generator. Berdasarkan pada Tabel 6, dapat dihitung efisiensi generator yang dapat dihasilkan oleh generator dengan persamaan berikut :

$$
\eta G \frac{\text { Pout }}{\text { Pin }} \times 100 \%
$$

Dimana:

Pout = daya output $(\mathrm{W})$

Pin = daya input $(\mathrm{W})$

Menurut perhitungan, efisiensi generator yang mampu dihasilkan oleh kincir angin adalah sebagai berikut: 


$$
\begin{aligned}
\eta G & =\frac{\text { Pout }}{\text { Pin }} \times 100 \% \\
& =\frac{5,36}{131,16} \times 100 \% \\
\eta G & =4,08 \%
\end{aligned}
$$

Hasil analisis selanjutnya dapat dilihat pada Tabel 8 .

\begin{tabular}{|c|c|c|}
\hline No & Pin (Watt) & Pout (Watt) \\
\hline 1 & 131,16 & 5,36 \\
\hline 2 & 96,77 & 7,2 \\
\hline 3 & 104,73 & 6,9 \\
\hline 4 & 163,54 & 16,61 \\
\hline 5 & 131,16 & 6,75 \\
\hline 6 & 59,67 & 2,42 \\
\hline 7 & 96,77 & 7,2 \\
\hline 8 & 98,07 & 7,25 \\
\hline 9 & 131,16 & 15 \\
\hline 10 & 96,77 & 7,2 \\
\hline 11 & 98,07 & 7,05 \\
\hline 12 & 96,77 & 7,45 \\
\hline 13 & 96,77 & 7,4 \\
\hline 14 & 96,77 & 7,05 \\
\hline 15 & 85,62 & 7,05 \\
\hline 16 & 78,68 & 2,44 \\
\hline 17 & 82,10 & 2,42 \\
\hline 18 & 78,68 & 2,44 \\
\hline 19 & 104,73 & 8,46 \\
\hline 20 & 88,02 & 18,2 \\
\hline 21 & 131,16 & 13,68 \\
\hline 22 & 201,90 & 22,22 \\
\hline 23 & 201,90 & 22,11 \\
\hline 24 & 176,69 & 19,6 \\
\hline 25 & 163,54 & 15,4 \\
\hline 26 & 104,73 & 7,15 \\
\hline 27 & 78,68 & 2,48 \\
\hline 28 & 163,54 & 15,4 \\
\hline 29 & 131,16 & 6,75 \\
\hline 30 & 96,77 & 6,55 \\
\hline 31 & 163,54 & 15,4 \\
\hline
\end{tabular}

Tabel 7. Rekapitulasi Hasil Perhitungan Pin Kincir Angin dan Pout Kincir Angin

Dari Tabel 8, didapatkan hasil bahwa efisiensi generator maksimum dan minimum yang dihasilkan berturut-turut adalah $20,68 \%$ dan $3,10 \%$. 
Tabel 8. Hasil Perhitungan Efísiensi Generator pada Kincir Angin

\begin{tabular}{|c|c|c|c|}
\hline No. & $\begin{array}{c}\text { Pin } \\
\text { (Watt) }\end{array}$ & $\begin{array}{c}\text { Pout } \\
\text { (Watt) }\end{array}$ & $\begin{array}{c}\text { Efisiensi } \\
\text { Generator } \\
(\%)\end{array}$ \\
\hline 1 & 131,16 & 5,36 & 4,08 \\
\hline 2 & 96,77 & 7,2 & 7,44 \\
\hline 3 & 104,73 & 6,9 & 6,59 \\
\hline 4 & 163,54 & 16,61 & 10,16 \\
\hline 5 & 131,16 & 6,75 & 5,15 \\
\hline 6 & 59,67 & 2,42 & 4,05 \\
\hline 7 & 96,77 & 7,2 & 7,44 \\
\hline No. & $\begin{array}{c}\text { Pin } \\
\text { (Watt) }\end{array}$ & $\begin{array}{c}\text { Pout } \\
\text { (Watt) }\end{array}$ & $\begin{array}{c}\text { Efisiensi } \\
\text { Generator } \\
(\%)\end{array}$ \\
\hline 8 & 98,07 & 7,25 & 7,39 \\
\hline 9 & 131,16 & 15 & 11,44 \\
\hline 10 & 96,77 & 7,2 & 7,44 \\
\hline 11 & 98,07 & 7,05 & 7,19 \\
\hline 12 & 96,77 & 7,45 & 7,70 \\
\hline 13 & 96,77 & 7,4 & 7,65 \\
\hline 14 & 96,77 & 7,05 & 7,29 \\
\hline 15 & 85,62 & 7,05 & 8,23 \\
\hline 16 & 78,68 & 2,44 & 3,10 \\
\hline 17 & 82,10 & 2,42 & 2,95 \\
\hline 18 & 78,68 & 2,44 & 3,10 \\
\hline 19 & 104,73 & 8,46 & 8,08 \\
\hline 20 & 88,02 & 18,2 & 20,68 \\
\hline 21 & 131,16 & 13,68 & 10,43 \\
\hline 22 & 201,90 & 22,22 & 11 \\
\hline 23 & 201,90 & 22,11 & 10,95 \\
\hline 24 & 176,69 & 19,6 & 11,09 \\
\hline 25 & 163,54 & 15,4 & 9,42 \\
\hline 26 & 104,73 & 7,15 & 6,83 \\
\hline 27 & 78,68 & 2,48 & 3,15 \\
\hline 28 & 163,54 & 15,4 & 9,42 \\
\hline 29 & 131,16 & 6,75 & 5,15 \\
\hline 30 & 96,77 & 6,55 & 6,77 \\
\hline 31 & 163,54 & 15,4 & 9,42 \\
\hline
\end{tabular}

\section{KESIMPULAN}

Berdasarkan hasil analisis yang dilakukan bahwa daya input yang dihasilkan pada kincir angin ini adalah 59,67 Watt sampai 201,90 Watt dan daya output yang dihasilkan pada kincir angin 2,42 Watt sampai 22,22 Watt. Efisiensi generator maksimum dan minimum yang dihasilkan berturut-turut adalah $20,68 \%$ dan $3,10 \%$. Hal ini menunjukan bahwa generator yang digunakan sudah efisien.

\section{REFERENSI}

[1] Abdul Kadir. 1995. Energi sumber daya, inovasi, tenaga listrik dan potensi ekonomi. Jakarta: UI-Press. 
[2] Alto Belly, dkk. 2010. DAYA AKTIF, REAKTIF \& NYATA. Diakses dari http://staff.ui.ac.id/system/files/users/chairul.hudaya/material/activereactiveandapparentpowe rpaper.pdf pada tanggal 23 Juni 2015, jam 13.30 WIB.

[3] Arthur Beiser. 1992. Konsep fisika modern. Jakarta: Erlangga.

[4] Dio Ananda Fitra Siregar. 2012. Pembangkit listrik tenaga bayu. Diakses dari http://www.getsttpln.com/ pada tanggal 9 April 2015, jam 8.00 WIB.

[5] Firmansyah Suryatmo. 1984. Teknik listrik motor \& generator arus bolak balik. Bandung: Alumni..

[6] Sucipto. 2008. Energi angin. Diakses dari http://digilib.itb.ac.id/ pada tanggal 29 Maret 2015, 15.00 WIB.

[7] Sunyoto. 1993. Mesin listrik arus searah. Yogyakarta: FPTK IKIP Yogyakarta [8] Panjaitan,R. 2000. Mesin Listrik Arus Bolak-Balik. Bandung : Tarsito. 